\title{
Evaluation of the dynamic response of structures using auxetic-type base isolation
}

\author{
Preyolin Naidoo \\ Structural Engineering and Computational Mechanics Group, Discipline of Civil Engineering, University of KwaZulu-Natal, \\ Durban, South Africa \\ preyolinnaidoo@gmail.com
}

\section{Georgios Drosopoulos*}

Structural Engineering and Computational Mechanics Group, Discipline of Civil Engineering, University of KwaZulu-Natal, Durban, South Africa

Howard College Campus, 4041, bttp:/ / secm.uk:zn.ac.zal

DrosopoulosG@ukzn.ac.za, https://orcid.org/0000-0002-4252-6321

\begin{abstract}
Base isolation is a widely-used method used to minimise the harmful effects of earthquakes on buildings. Unlike a fixed base building, a building with a base isolation system essentially decouples the superstructure from the substructure resting on the ground. Then, during earthquakes, the superstructure's relative displacement is significantly reduced, minimising the structural damage. Auxetics, which are materials with a negative Poisson's ratio, are known for possessing properties such as high energy absorption. Based on the energy absorbing capabilities of auxetic materials, it is proposed that incorporating them into base isolation structures would positively impact on the performance of the system. Therefore, the article aims to investigate the response of structures under seismic loading incorporating re-entrant hexagon layers into the base isolation system. This is assessed by defining and numerically testing the system using finite element analysis. The models developed for this study represent multi-story structural steel frames combined with fixed base, conventional lead-rubber bearing and auxetic composite base isolation. Differences in the response obtained from the mentioned systems are highlighted. Results indicate that the auxetic base isolation may improve the dynamic response of structures, although a unique performance is not recorded.
\end{abstract}

KEYwORDS. Auxetic Materials; Seismic Actions; Base Isolation; Finite element analysis; Structural Damage.

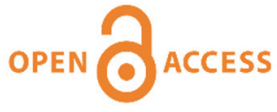

Citation: Naidoo, P, Drosopoulos, G., Evaluation of the dynamic response of structures using auxetic-type base isolation, Frattura ed Integrità Strutturale, 51 (2020) 5270.

Received: 17.05 .2019 Accepted: 28.09 .2019 Published: 01.01.2020

Copyright: (C) 2020 This is an open access article under the terms of the CC-BY 4.0, which permits unrestricted use, distribution, and reproduction in any medium, provided the original author and source are credited. 


\section{INTRODUCTION}

$\mathrm{T}$ he impact of earthquakes on structures has historically resulted in large scale damage, leading to great financial implications and human loss. This has led to multiple alterations of the seismic design philosophy of structures in earthquake prone areas. Some improvements to the design criteria include the increase of the lateral strength and ductility of structures. However, due to high construction costs, among other factors, it is not practically feasible to increase a building's strength indefinitely.

The concept of decoupling a structure from its substructure was introduced as a method of isolating it from the harmful effects of the earthquake. Base isolation systems aim to reduce the physical demand placed on a building to resist seismic actions. By incorporating base isolation into a building, this relieves the building's structural components from the role of dissipating seismic energy and significantly reduces the structure's relative displacements induced by the seismic waves.

The most frequently used types of base isolation can be divided into two categories, thus, sliding bearings and laminated rubber bearings [1]. Sliding base isolation systems operate on the fundamental mechanism of frictional sliding, whereby a frictional force within the system resists motion induced by the seismic vibration and dissipates its energy [2]. Laminated rubber bearings consist of alternating layers of rubber and steel plates. The steel plates within the base isolators assist the system by increasing its vertical stiffness.

Another type of laminated rubber bearing, which is used in this article, is the lead-core or lead-plug rubber bearing. This type of laminated bearing is comprised of alternating cylindrical or square rubber bearings and steel plates. Additionally, at the centre of the base isolator, a short cylindrical core or plug made of lead is located. This system provides a great deal of stiffness under the considerable vertical load from the superstructure and is simultaneously flexible under horizontal loading obtained from an earthquake [3]. According to the work presented in [4], the damping ability of natural rubber is limited to $2-3 \%$ of the critical viscous damping. This is relatively low and therefore negatively impacts on the bearing's ability to dissipate seismic energy. Due to this property, the base isolation system may incorporate a lead core to provide additional damping to the system.

The goal of this study is to numerically test and compare traditional base isolation systems described above and alternative systems with auxetic patterns in their structure. Auxetics, are materials with negative Poisson's ratio. Unlike conventional materials, they experience a contraction in the transverse direction while under compression and expand while under tension. In [5] has been found that all auxetic materials possess a microstructure which is appropriate to activate negative Poisson's ratio behaviour. This microstructure generally involves a deformation pattern such as hinging, rotating, stretching or bending. While most auxetic materials are made of porous foams or hinged metamaterials with re-entrant type microstructures, natural auxetic materials also exist [6].

The simplest auxetic structure is based on the general shape of a bow tie [7]. The 'bow tie' auxetic structure is more commonly known as the re-entrant hexagon structure. This structure is a modified, non-convex or inverted form of a simple hexagon structure. A conventional hexagonal or honeycomb structure presents a typical positive Poisson's ratio behaviour when it is exposed to a lateral load. By slightly reorienting the hexagonal geometry to adopt a re-entrant structure, the modified honeycomb is seen to exhibit an auxetic behaviour. The re-entrant hexagon structure is anisotropic in nature, displaying different Poisson's ratio values when loaded about the $\mathrm{x}$ and $\mathrm{y}$ axes respectively $[5,8]$.

The field of auxetic materials has been developed substantially and several auxetic systems have been tested both numerically and experimentally. In addition to the re-entrant hexagon, other extensively researched auxetic structures include rotating rectangles and triangles, arrowhead and star shaped arrangements [9]. These auxetic structures have been manufactured into foams, polymers, composites and metals [10].

A study carried out in [11] analysed the static and dynamic properties of polyurethane foams with an auxetic microstructure. The conducted tests aimed to evaluate the vibration reduction properties of foams for use in gloves in order to protect workers from the harmful effects of mechanical vibrations. In comparison to non-auxetic polyurethane foam, the auxetic foam exhibited a notable increase in stiffness under compression. More studies have also indicated the significant effects of the Poisson's ratio of auxetics, on their mechanical properties [10,12, 13, 14, 15]. An investigation on two-dimensional reentrant hexagon structures presented in [10], found that the vibration isolation performance of these structures depends on various geometric properties of the auxetic cells. Numerical analysis results have shown that optimisation of the cell thickness and cell angle of auxetics, results in a significant increase in the vibration level difference, when compared to preliminary models. The idea of application of locally resonant metamaterial structures for seismic isolation purposes is also elaborated in [16]. In [7] is proposed that properly designed mechanical metamaterials such as auxetics, can result in band gaps at frequencies compatible with seismic waves, enabling the usage of these materials for seismic isolation. Similar results, indicating the capability of auxetics to reduce the propagation of imposed vibration, are presented in $[6,17]$. 
Due to these advanced properties, the development of auxetic materials has been incorporated in various fields such as the automobile and aerospace industries, the medical field, the defence industry (particularly in high-performance body armour) and in sports equipment $[10,18]$. More research on auxetic structures' performance under vibration conditions can be found in $[19,20,21,22,23]$.

In this article, a numerical, finite element study is presented for the analysis and evaluation of a base isolation system which incorporates re-entrant hexagonal auxetic layers into its design. Thus, based on the vibrational damping performance of auxetic materials found in literature, the usage of auxetic materials in base isolation systems is explored. Eigenvalue as well as non-linear time history analysis using ground motions obtained from old earthquakes have been considered, to tests numerical models representing multi-story structural steel frames. For these studies, fixed base, conventional lead-rubber bearing and auxetic composite base isolation systems have been applied. Differences in the response obtained from these systems are highlighted and compared with the fixed base frame which serves as a baseline for evaluating the base isolated models.

\section{AUXETIC MATERIALS}

$\mathrm{P}$

oisson's ratio is a numerical indication of a material's performance under deformation. When a material is under a compressive force, it expands in the direction perpendicular to the force. Likewise, should a tensile force be applied to the material, it will contract in the direction perpendicular to the force. Therefore, Poisson's ratio is defined as the negative ratio of lateral strain to axial strain, i.e. $v=(-$ Lateral strain) $/$ (Axial strain).

The mentioned behaviour represents conventional materials with positive Poisson's ratio. However, there is a group of materials called auxetics, possessing negative Poisson's ratio. Unlike conventional materials, these auxetic or negative Poisson's ratio (NPR) materials experience a contraction in the transverse direction while under a compressive force and expand while under a tensile force. Fig. 1 provides a graphical representation of the deformation of both positive and negative Poisson's ratio materials, as well as an example of an auxetic microstructure, where a star-shaped auxetic structure is presented [24].

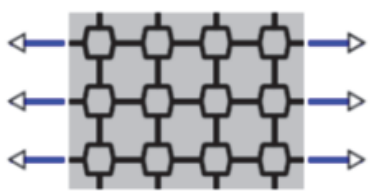

(a)

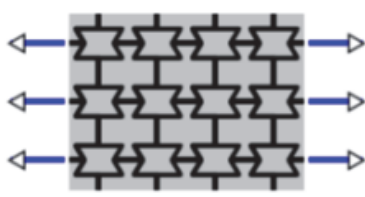

(b)
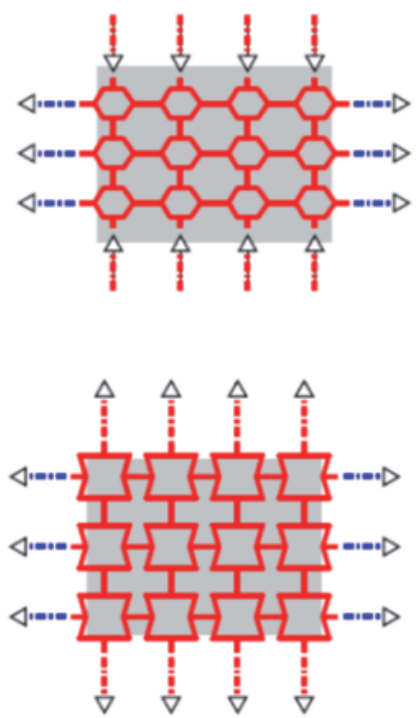

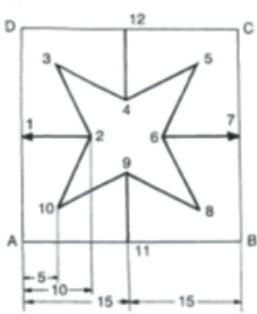

(c)

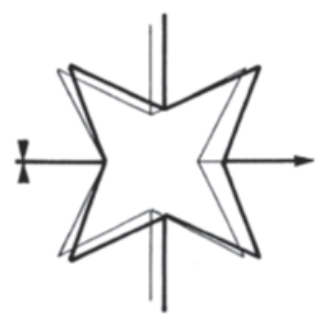

(d)

Figure 1: (a) Conventional, (b) Auxetic behaviour of microstructures based on their internal substructure, (c) Star-shaped, twodimensional representative auxetic cell (d) Deformation of the star-shaped cell.

\section{DESIGNING TRADITIONAL AND AUXETIC BASE ISOLATION}

he goal of this research is to investigate if the incorporation of an auxetic microstructure into a base isolation system, could lead to the improved dynamic response of multi-story structures under seismic actions. To conduct this investigation, numerical finite element models are developed, simulating the superstructure and base isolation systems. 


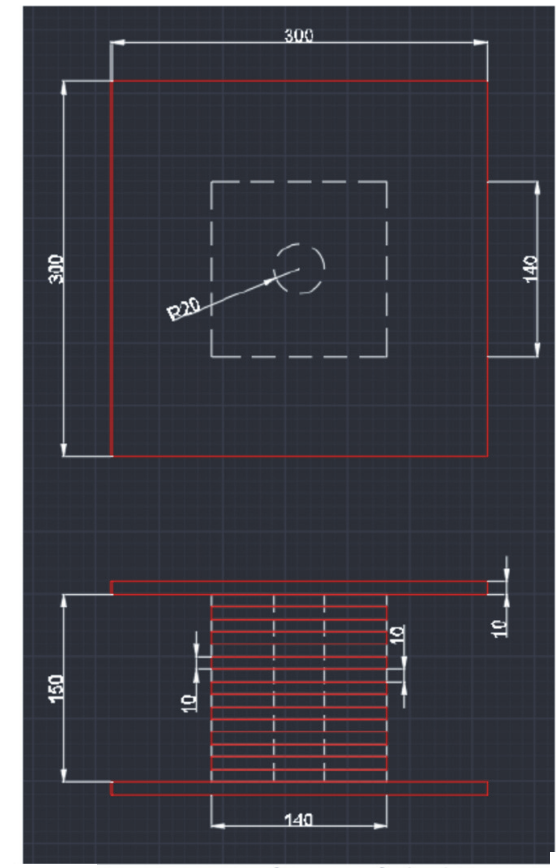

(a)

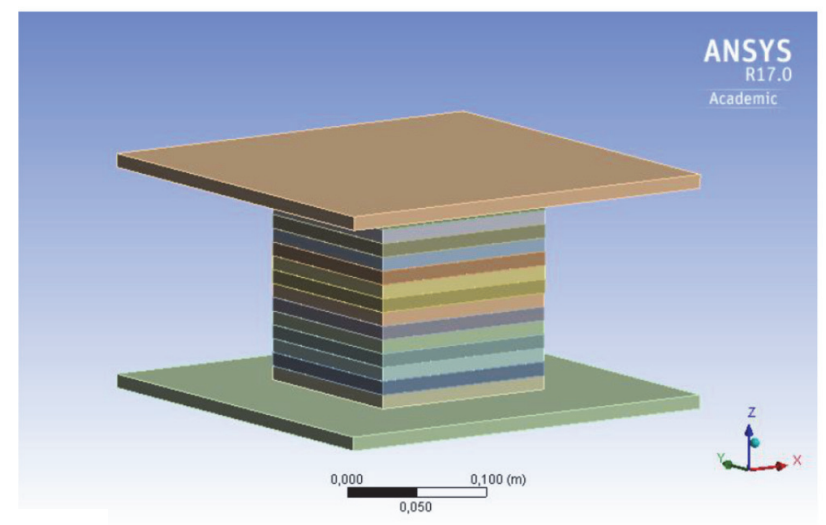

(b)

Figure 2: (a) Geometry of typical Lead-Rubber Bearing base isolator (mm), (b) Three-dimensional isometric view of the Lead-Rubber Bearing base isolator model.

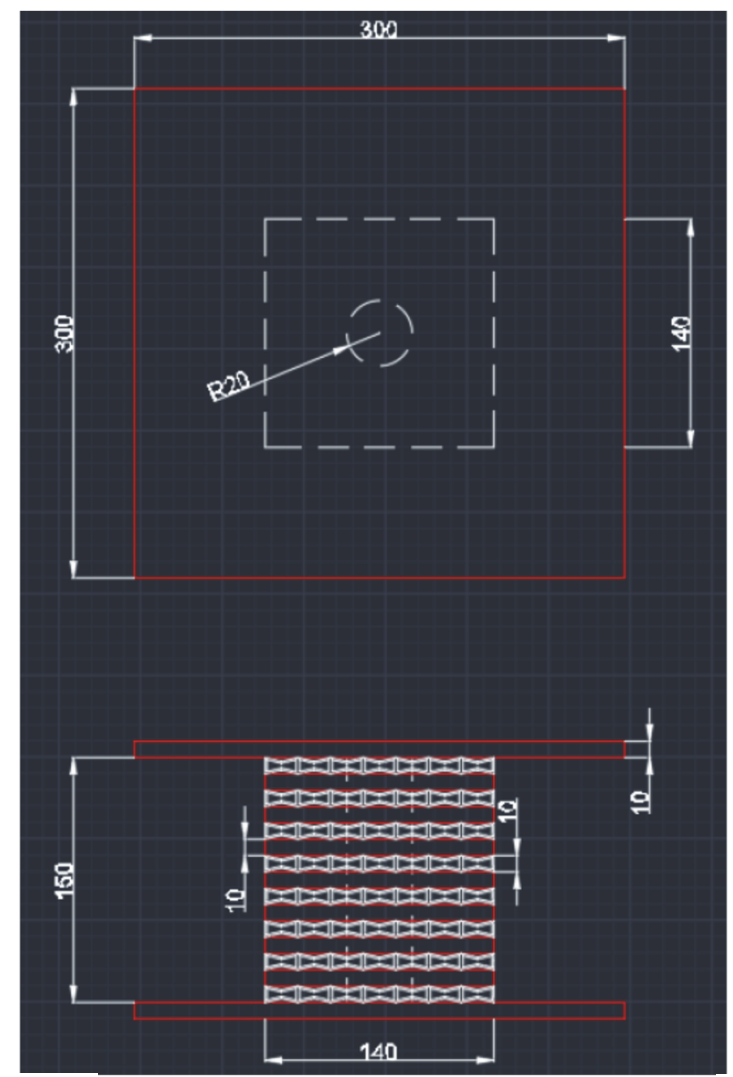

(a)

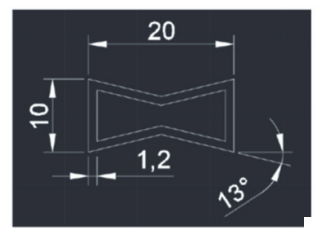

(b)

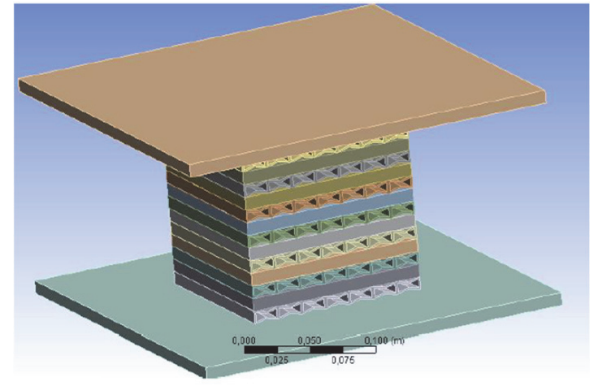

(c)

Figure 3: (a) Geometry of Auxetic type base isolator (mm), (b) Geometry of Re-Entrant hexagon cell (mm), (c) Three-dimensional isometric view of the Auxetic type base isolator model. 
In particular, to assess the performance of a steel multi-story building under earthquake loading, a conventional lead-rubber bearing (LRB) and an auxetic composite base isolation have been designed. The dimensions and general configuration of the auxetic-type base isolator were chosen to be similar to that of the LRB in order to evaluate the two systems based on the same geometric criteria. The developed three-dimensional geometries have been incorporated in finite element analysis software (ANSYS), to model the response of the isolated superstructure. Results from a fixed structure, where no base isolation is applied, will also be presented.

The lead-rubber bearing base isolator consists of steel layers between rubber layers of the same dimensions and has a height of $0.15 \mathrm{~m}$. In the middle of these layers, lies the lead core with a height of $0.15 \mathrm{~m}$ and a radius of $0.02 \mathrm{~m}$. At both the top and the bottom of the base isolator, two $0.3 \mathrm{~m}$ x $0.3 \mathrm{~m}$ x $0.01 \mathrm{~m}$ steel plates have been designed. The bottom steel plate is fixed to the ground and the top steel plate is bonded to the bottom faces of the superstructure. Fig. 2 depicts a typical crosssection and top view of the LRB, as well as a three-dimensional view of the base isolator.

The dimensions of the auxetic-type base isolator are shown in Fig. 3a. In this model, the rubber layers in the LRB base isolator have been replaced with auxetic layers. The auxetic cell chosen for this study is a re-entrant hexagon. As illustrated in Fig. 3b, the cell height and width are $0.01 \mathrm{~m}$ and $0.02 \mathrm{~m}$ respectively, while the cell angle is $13^{\circ}$. Fig. $3 \mathrm{c}$ shows a threedimensional view of the auxetic-type base isolator.

\section{SUPERSTRUCTURE}

he main structural system, thus the superstructure, is a multi-story steel building. It consists of beams and columns made of $203 \times 203 \times 46 \mathrm{H}$ Sections as defined in [25]. It is a ten-story structure with a story height of $3.5 \mathrm{~m}$ and a floor dimension of $5 \mathrm{~m} \times 5 \mathrm{~m}$. The total height of the superstructure is $35 \mathrm{~m}$. In the case of the fixed frame model, fixed supports are considered on the base of the four steel columns.

\section{FinITE ELEMENT ANALYSIS}

\section{Material properties}

7 he models which are developed in the study consist of three materials: lead, rubber and steel. Rubber is the material used in the rubber bearings and the auxetic layers, while lead is used as the core in both isolation systems. S355 steel is used in the superstructure and the steel plates in both the LRB and auxetic-type isolators. Tab. 1 shows the material properties for the mentioned materials [26,27]. In order to determine the plastic behaviour of steel (which is needed for the solution of the non-linear time-history analysis) indicating damage, a multilinear isotropic hardening law using true stresses vs strains, is adopted in Fig. 4, [28]. For the purpose of this study, only a linear elastic law has been considered for the lead core. It is also noted that linear tie constraints between the layers of each base isolation (not allowing for opening or sliding between the layers) have been considered.

\begin{tabular}{lccc}
\hline Property & Lead & Rubber & Steel \\
Density $\left(\mathrm{kg} / \mathrm{m}^{3}\right)$ & 11340 & 1200 & 7850 \\
Young's Modulus $(\mathrm{MPa})$ & 14000 & 100 & 200000 \\
Poisson's Ratio & 0.43 & 0.48 & 0.3 \\
\hline
\end{tabular}

Table 1: Material properties.

\section{Mesh for each of the structural parts}

For every structural part, three dimensional, hexagonal, 8-node elements are used. To reduce the computational time of each simulation, a reduced integration scheme with one Gauss point per element is adopted. Tab. 2 shows the number of nodes and elements used for each of the developed models. In Fig. 5 a part of the mesh of the superstructure is shown. In Fig. 6 the mesh of the conventional and the auxetic base isolator are given. It is noted that this was the best (densest) mesh 
that could be adopted for these studies, considering restrictions related to the computational capacity of the used personal computer.

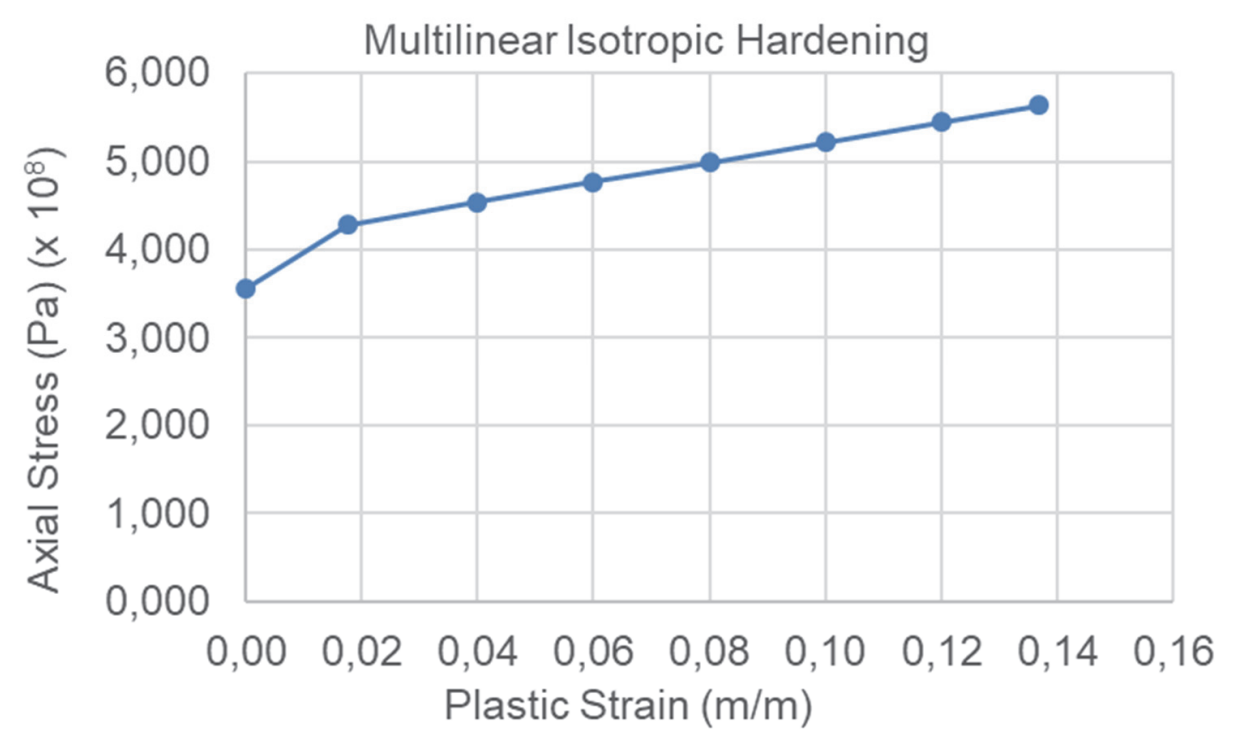

Figure 4: Stress-strain law adopted for structural steel.

\begin{tabular}{lcc}
\hline Model & No. of Nodes & No of Elements \\
Fixed Frame & 21484 & 15448 \\
LRB & 26934 & 16480 \\
Auxetic-Type & 54642 & 116976 \\
\hline
\end{tabular}

Table 2: Number of nodes and elements per model.

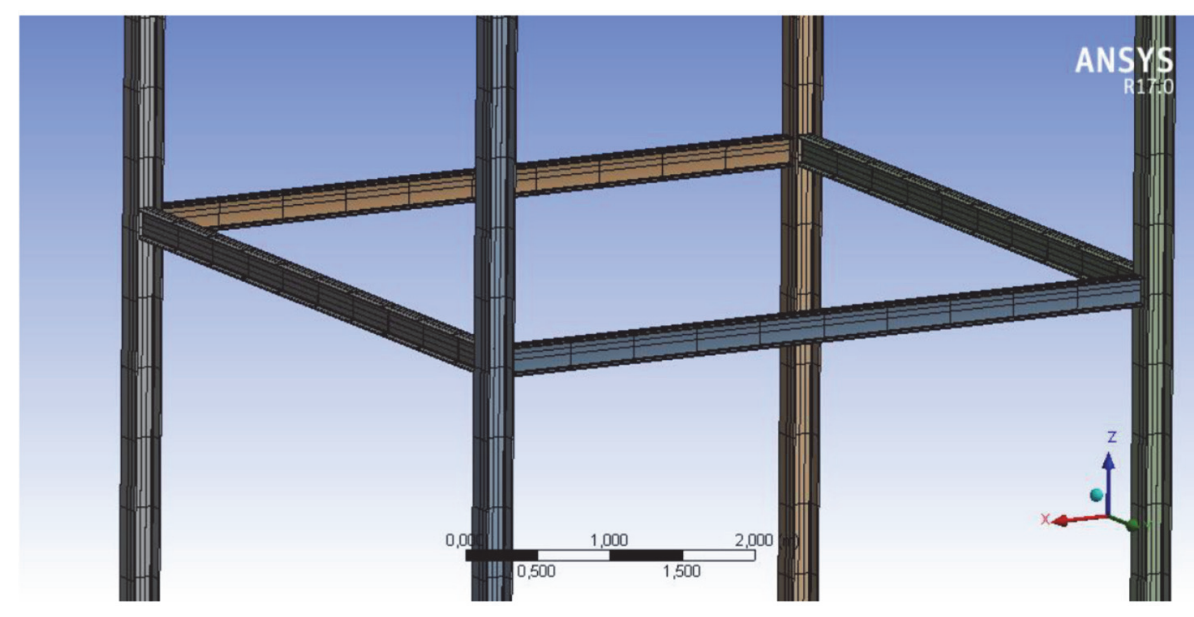

Figure 5: Mesh of the steel superstructure. 

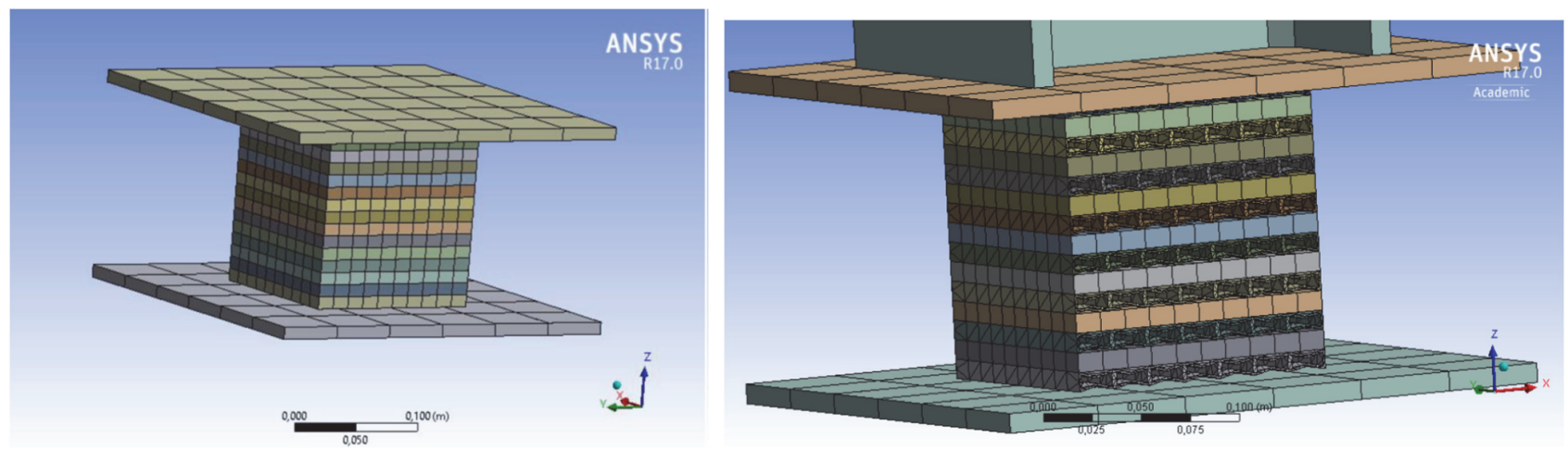

Figure 6: Mesh of the conventional and the auxetic base isolation.

\section{Loading of the structural system}

An eigenvalue analysis is initially performed to determine the eigenfrequency associated with each mode of the developed models. Subsequently, the eigenperiod is calculated for each mode, as the inverse of the eigenfrequency. It is noted that in a base isolation study, the base isolated system is expected to depict an increased eigenperiod of the model due to the increase of the lateral flexibility at the base. For the analyses performed, a total of 20 eigenvalues were calculated.

To determine the seismic performance of the structural system, non-linear time history analysis has also been performed. A time history analysis enables seismic loading to be applied to the model as a ground motion record (acceleration versus time diagram). To model this earthquake loading, past seismic events have been used. In particular, the earthquakes used for the analysis occurred in Irpinia, Italy; Düzce, Turkey and Northridge, California. Tab. 3 details the characteristics and data available of the three earthquakes and Fig. 7 provide a visual representation of the $\mathrm{x}, \mathrm{y}$ and $\mathrm{z}$ components of the ground motions, as ground acceleration versus time graphs.

\begin{tabular}{|c|c|c|c|}
\hline Earthquake & Northridge 1 & Irpinia & Düzce \\
\hline Location & California, USA & Italy & Turkey \\
\hline Year & 1994 & 1980 & 1999 \\
\hline Magnitude & 6.69 & 6.9 & 7.15 \\
\hline Epicentral distance $(\mathrm{km})$ & 25.42 & 30.35 & \\
\hline Site class & B & B & \\
\hline Peak Ground Acceleration (PGA) (g) & 0.2458 & 0.29 & \\
\hline Total Duration (a) & 46.935 & 39.340 & 43.150 \\
\hline Duraration of Inteval Used (s) & 15.000 & 15.048 & 15.000 \\
\hline Time Interval Used (s) & $0-15.0$ & $0-15.048$ & $15.0-30.0$ \\
\hline
\end{tabular}

Table 3: Earthquake data.

\section{RESULTS AND DISCUSSIONS}

he response and performance of auxetic type base isolation systems under seismic loading will be investigated in this section. Furthermore, their performance is evaluated with respect to that of a traditional lead-rubber bearing base isolation system and a fixed base system. 

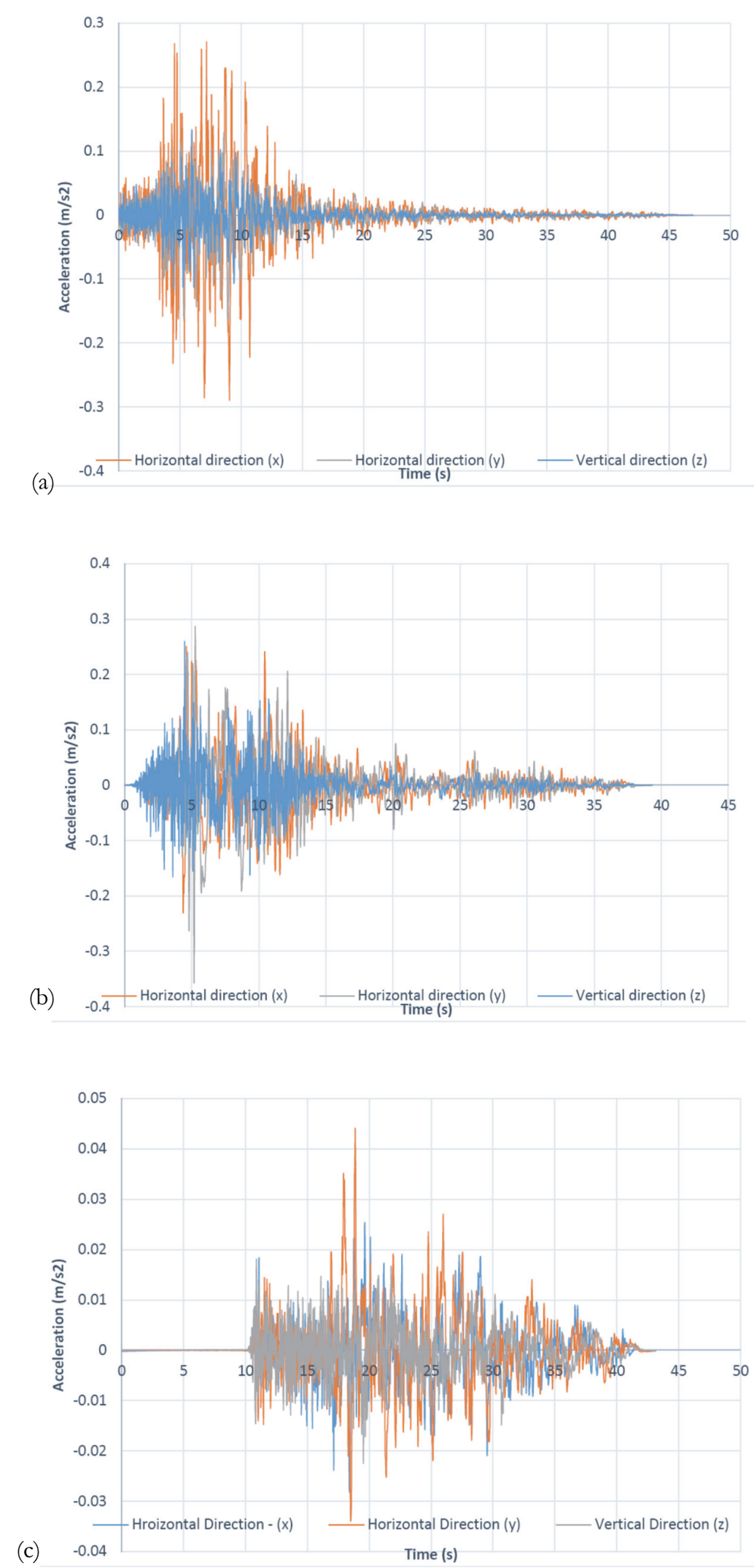

Figure 7: Ground motion records of (a) Northridge Earthquake - California, USA 1994, (b) Irpinia Earthquake - Italy 1980, (c) Düzce Earthquake - Turkey 1999. 


\section{Eigenvalue analysis}

The eigenvalue analysis is performed to determine the natural frequency, natural period and mode shapes of each system. Tab. 4 presents results from the eigenvalue analysis carried out on the three systems. With the addition of the auxetic base isolation, the new natural period of the structure is significantly longer when compared to the natural period of the fixedbase structure. By elongating the natural period of a structure using base isolation, it is possible to reduce the base acceleration experienced by the structure. This in turn potentially reduces the development of damage on the structural system during an earthquake. In particular, it can be seen in Tab. 4 that the auxetic base isolation depicts higher eigenperiod values than the other two systems. The LRB system, experiences higher eigenperiods than the fixed frame for the first three modes, (which are expected to significantly influence the vibration of the system), after which the eigenperiods are slightly reduced.

\begin{tabular}{|c|c|c|c|c|c|c|}
\hline \multirow[t]{2}{*}{ No. } & \multicolumn{2}{|c|}{ Fixed Frame } & \multicolumn{2}{|c|}{ LRB } & \multicolumn{2}{|c|}{ Auxetic-Type } \\
\hline & Frequency $(\mathrm{Hz})$ & Period (s) & Frequency $(\mathrm{Hz})$ & Period (s) & Frequency $(\mathrm{Hz})$ & Period (s) \\
\hline 1 & 1.2296 & 0.814 & 1.196 & 0.836 & 0.509 & 1.965 \\
\hline 2 & 1.977 & 0.506 & 1.914 & 0.522 & 0.572 & 1.749 \\
\hline 3 & 3.836 & 0.261 & 3.782 & 0.264 & 1.248 & 0.801 \\
\hline 4 & 6.018 & 0.166 & 6.136 & 0.163 & 1.887 & 0.530 \\
\hline 5 & 6.152 & 0.163 & 6.988 & 0.143 & 2.322 & 0.431 \\
\hline 6 & 6.896 & 0.145 & 8.296 & 0.121 & 2.721 & 0.367 \\
\hline 7 & 7.357 & 0.136 & 9.397 & 0.106 & 3.680 & 0.272 \\
\hline 8 & 8.043 & 0.124 & 10.547 & 0.095 & 4.110 & 0.243 \\
\hline 9 & 9.684 & 0.103 & 10.695 & 0.094 & 4.600 & 0.217 \\
\hline 10 & 10.092 & 0.099 & 11.183 & 0.089 & 5.102 & 0.196 \\
\hline 11 & 10.336 & 0.097 & 11.540 & 0.087 & 5.329 & 0.188 \\
\hline 12 & 10.511 & 0.095 & 12.740 & 0.078 & 6.398 & 0.156 \\
\hline 13 & 12.837 & 0.078 & 14.450 & 0.069 & 6.520 & 0.153 \\
\hline 14 & 13.636 & 0.073 & 14.703 & 0.068 & 6.934 & 0.144 \\
\hline 15 & 14.303 & 0.070 & 15.335 & 0.065 & 7.349 & 0.136 \\
\hline 16 & 15.164 & 0.066 & 15.335 & 0.065 & 8.147 & 0.123 \\
\hline 17 & 16.849 & 0.059 & 15.335 & 0.065 & 8.325 & 0.120 \\
\hline 18 & 18.119 & 0.055 & 15.335 & 0.065 & 8.812 & 0.113 \\
\hline 19 & 18.710 & 0.053 & 15.649 & 0.064 & 9.083 & 0.110 \\
\hline 20 & 20.153 & 0.050 & 15.799 & 0.063 & 9.981 & 0.100 \\
\hline
\end{tabular}

Table 4: Eigenvalue analysis results.

Figs. 8-10 represent various mode shapes obtained from each system. According to these figures, the mode shapes of the base isolated structures may present differences when compared to the fixed-base system. 


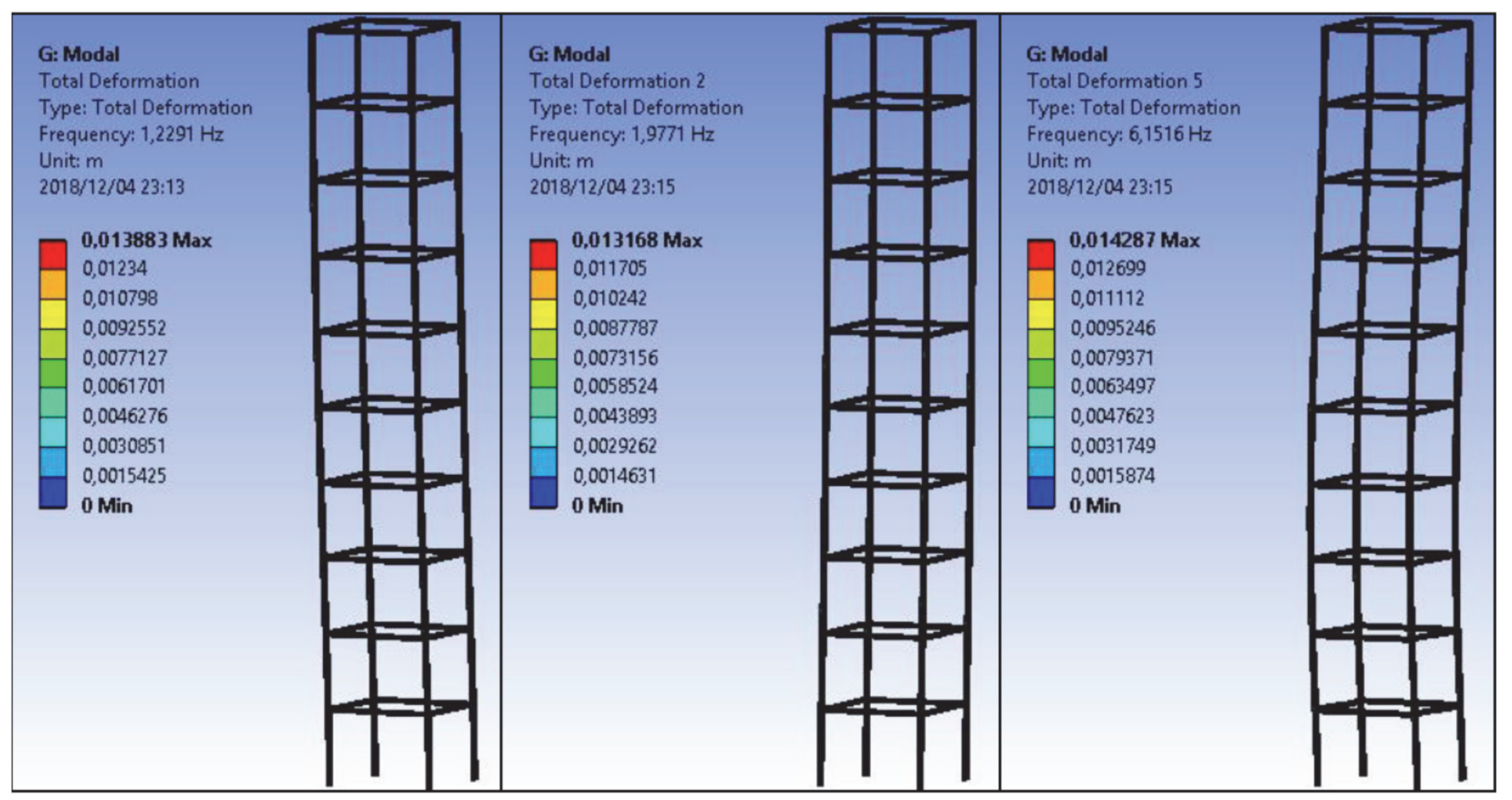

Figure 8: Mode Shapes 1, 2 and 5 of the fixed frame.

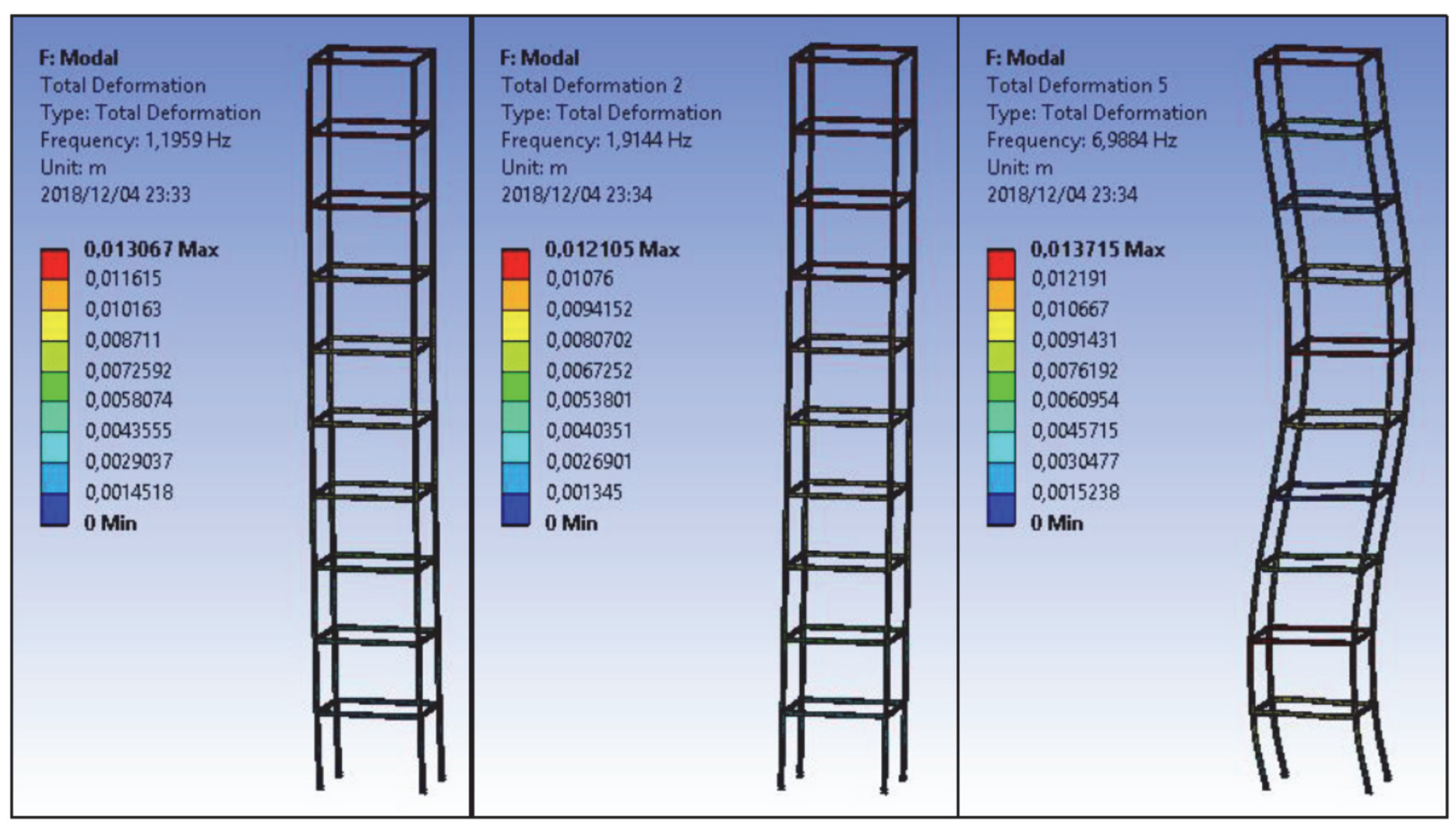

Figure 9: Mode Shapes 1, 2 and 5 of the LRB system. 


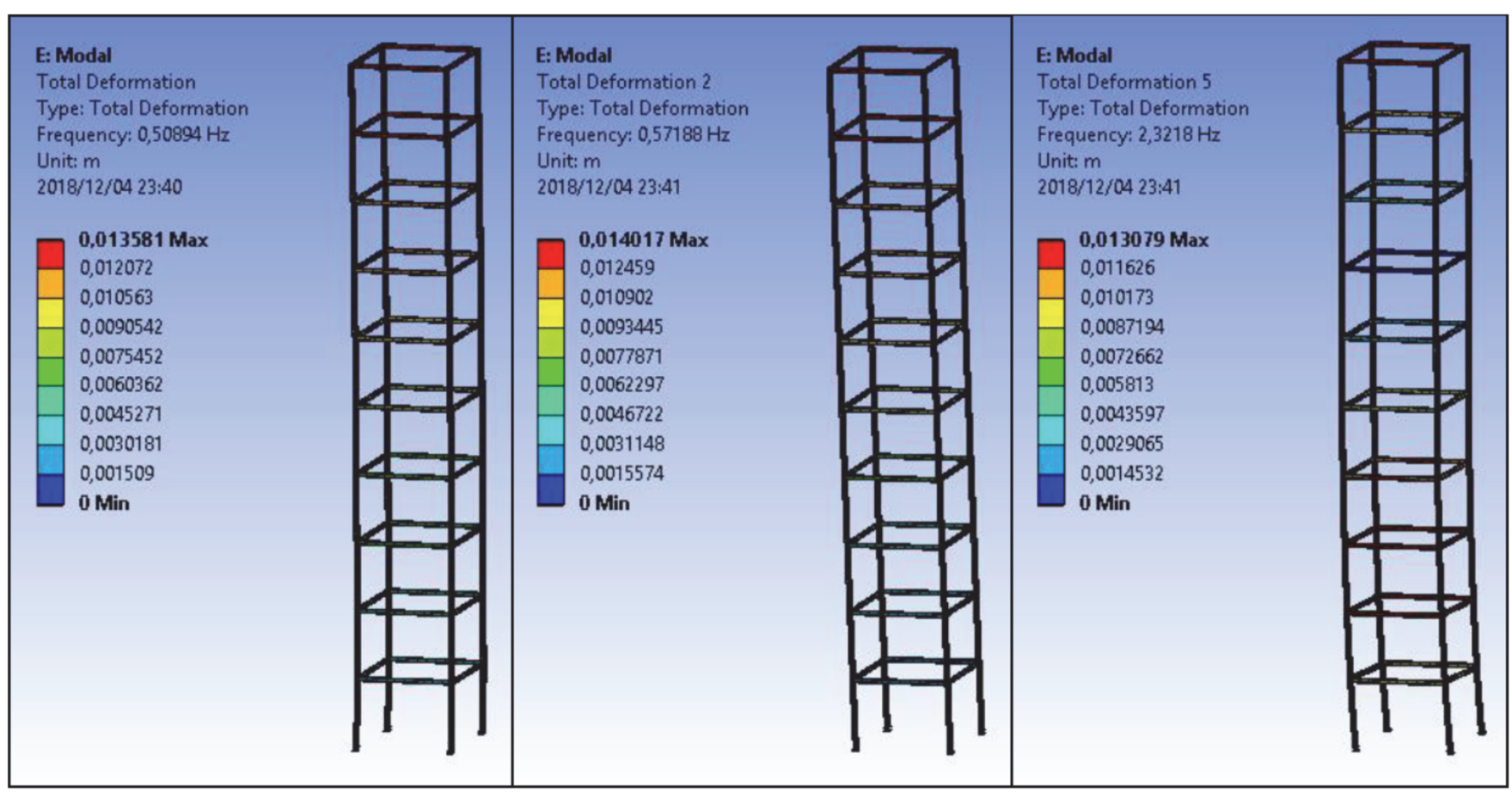

Figure 10: Mode Shapes 1, 2 and 5 of the Auxetic system.

\section{Nonlinear time bistory analysis}

A non-linear time history analysis is performed on the ten-story steel frame with a fixed base. The analysis uses seismic data obtained from the Irpinia, Italy; Düzce, Turkey and Northridge, California earthquakes. Similar analyses are performed on the structure with lead-rubber bearing and auxetic type base isolation systems. In all three investigations, the steel components in the models possess non-linear properties (material and geometric nonlinearity). The performance of the systems has been evaluated at the bottom, middle and top of the superstructure i.e. floors $1-2,5-6$ and $9-10$.

\section{- Northridge earthquake, California 1994}

The 6.69 magnitude Northridge earthquake occurred in California, USA in 1994. It can be described as a very intense event, most impulsive along the $\mathrm{x}$-axis, with minor vibrations occurring from 12 seconds onwards. The most seismically severe portion of the earthquake was used in the analysis i.e. $0-15$ seconds.

The total relative displacement refers to the average displacement over time along each axis i.e. ux, uy and uz, between two consecutive floors. Reducing the overall relative displacements of stories is one of the primary objectives of base isolation. By doing so, the possibilities of both structural and non-structural damage are significantly reduced, since the elastic forces which are developed in the structure due to inertial effects, are also reduced. As shown in Figure 11, the auxetic-type system exhibits a favourable performance at all three levels, along with the height of the structure. In the lower levels, the auxetic base isolated structure occasionally displays an improved performance, in respect to the fixed structure. At the middle of the superstructure, the auxetic system has performed particularly well with almost overall lower relative displacements than the LRB and fixed systems. In the upper floors, all three systems have behaved in a comparatively similar manner. From $t$ $=5-9 \mathrm{~s}$, the auxetic system has responded with relative displacements exceeding those of the other two systems. But except this period, the proposed auxetic base isolation seems to perform well, depicting a reduction in the relative displacement between the floors, as compared to the fixed frame and LRB base isolation.

The reduction of the total acceleration in each floor as a result of the imposed seismic loading is considered to be a notable performance indicator of base isolation systems. The analysis considered the total story acceleration at the first, fifth and tenth floor in order to evaluate the acceleration reduction. The general trend illustrated in Fig. 12 reveals that generally, the auxetic-type system experienced significantly lower story accelerations when compared with the LRB and fixed base systems. On the first floor, the auxetic-type system's performance is slightly better than the fixed base system. However, as the story height increases, the acceleration reduction capabilities offered by the auxetic system becomes more evident and for the latter part of the ground motion, it performs notably better than the LRB system. It should be noted that accelerations 
higher than the fixed structure, were present in the LRB system on the first floor. On floors five and ten, the total acceleration mostly matched or slightly exceeded that of the fixed base system, however during certain portions of the earthquake, the total acceleration experienced has been improved.
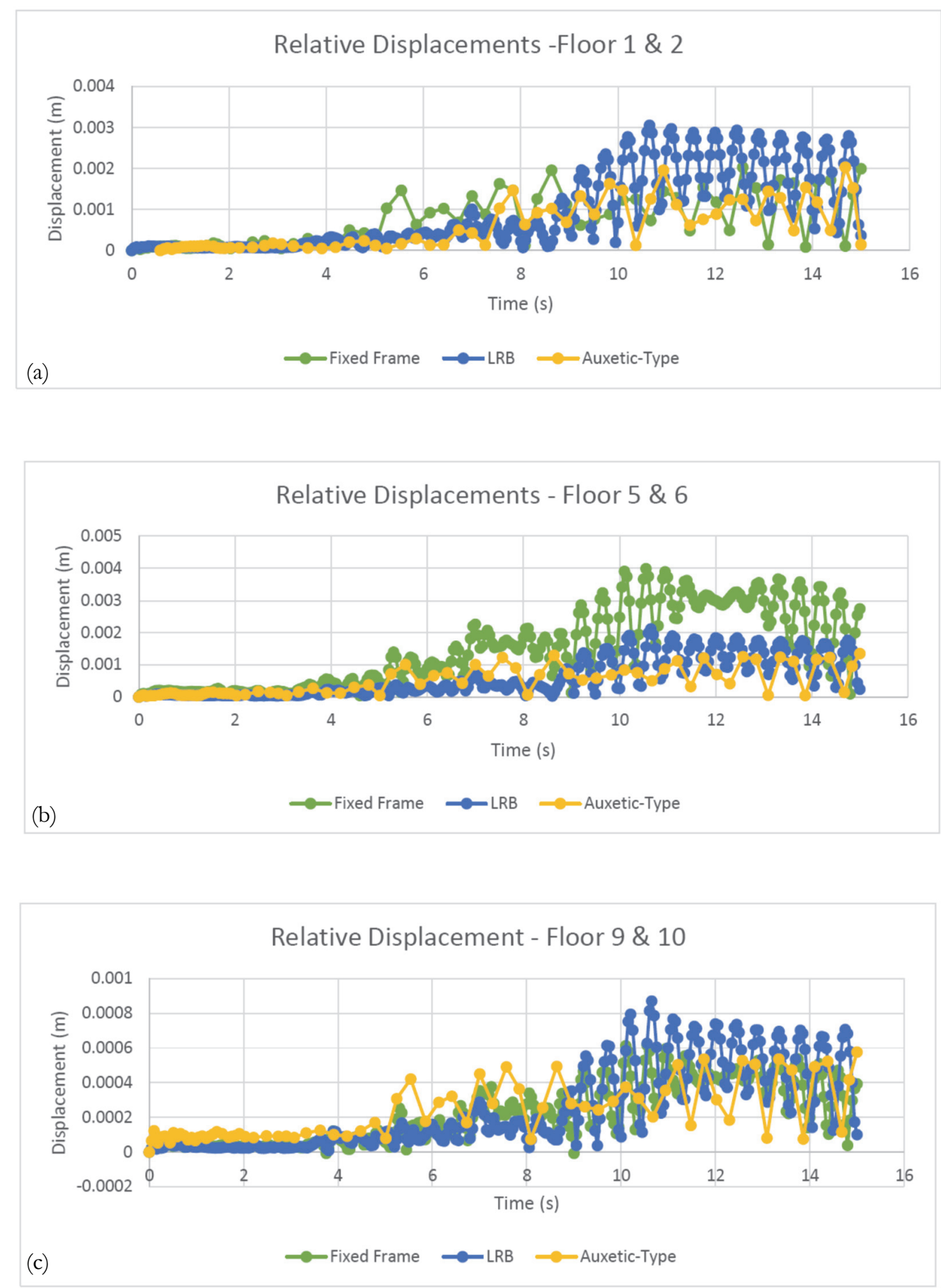

Figure 11: Relative displacement of floors (a) 1 and 2, (b) 5 and 6, (c) 9 and 10 

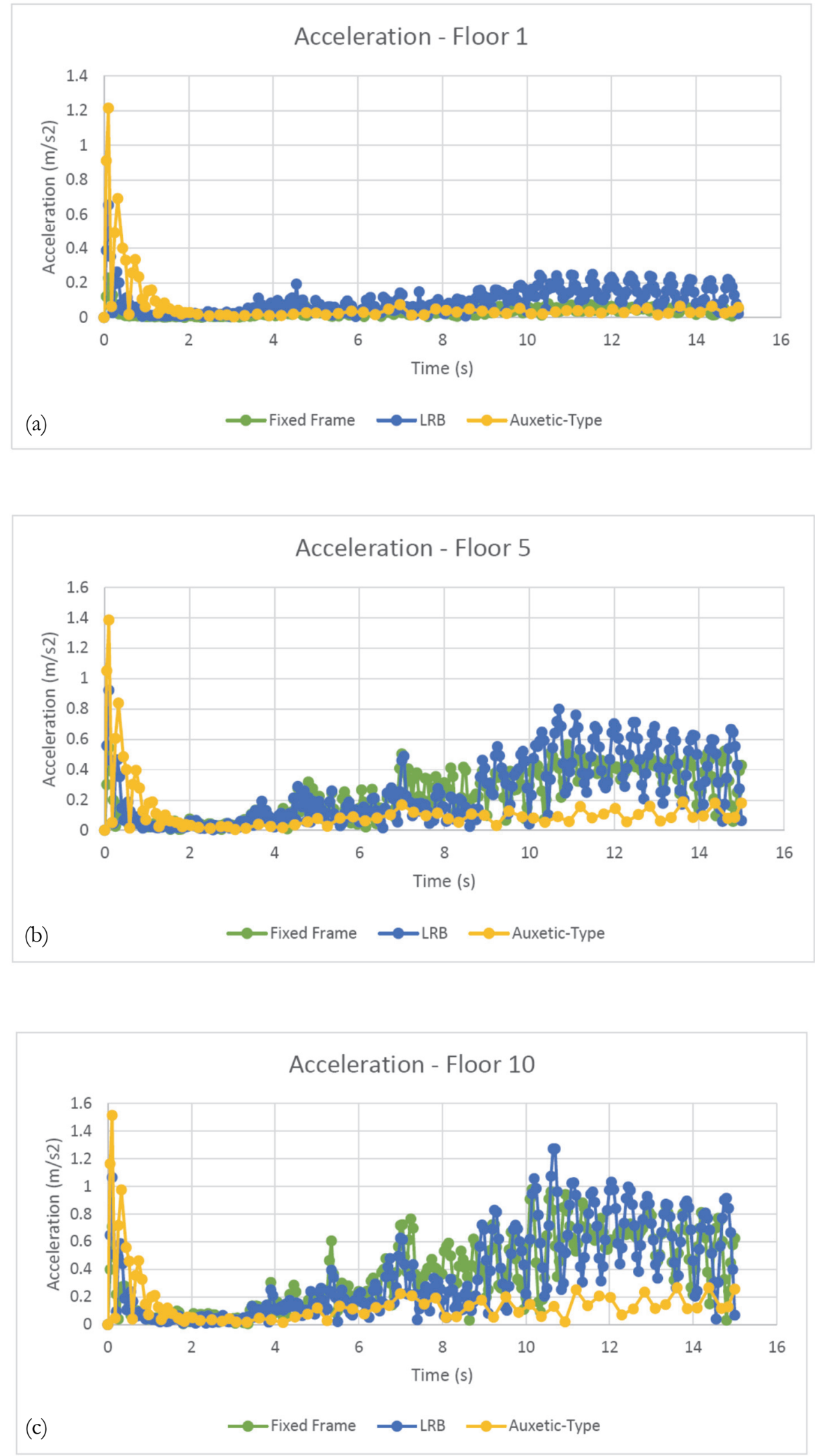

Figure 12: Acceleration on floor (a) 1, (b) 5, (c) 10 
- Irpinia earthquake, Italy 1980

The Irpinia earthquake occurred in Italy in 1980 and had a magnitude of 6.9. Like Northridge, Irpinia can be described as an intense event in the early stages of the ground motion which slowly tapers off after 15 seconds. The earthquake's strongest vibrations occur along the $\mathrm{Y}$-axis, however vibrations along the $\mathrm{X}$ and $\mathrm{Z}$ axes are significantly close to that of the $\mathrm{Y}$-axis vibrations. The interval of $0-15$ seconds was noted as the most intense portion of the earthquake and was therefore used in the analysis.

As shown in Fig. 13, the auxetic-type system exhibits a favourable performance for most of the duration of the earthquake at the lower floors. However, on the upper floors, the performance is only favourable for the first part of the earthquake, between $\mathrm{t}=0-4 \mathrm{~s}$. Following this initial stage of the loading, the relative displacements of the auxetic base isolated structure exceed that of the other two systems. The LRB system has almost consistently shown a reduction in relative displacements throughout the three levels evaluated.
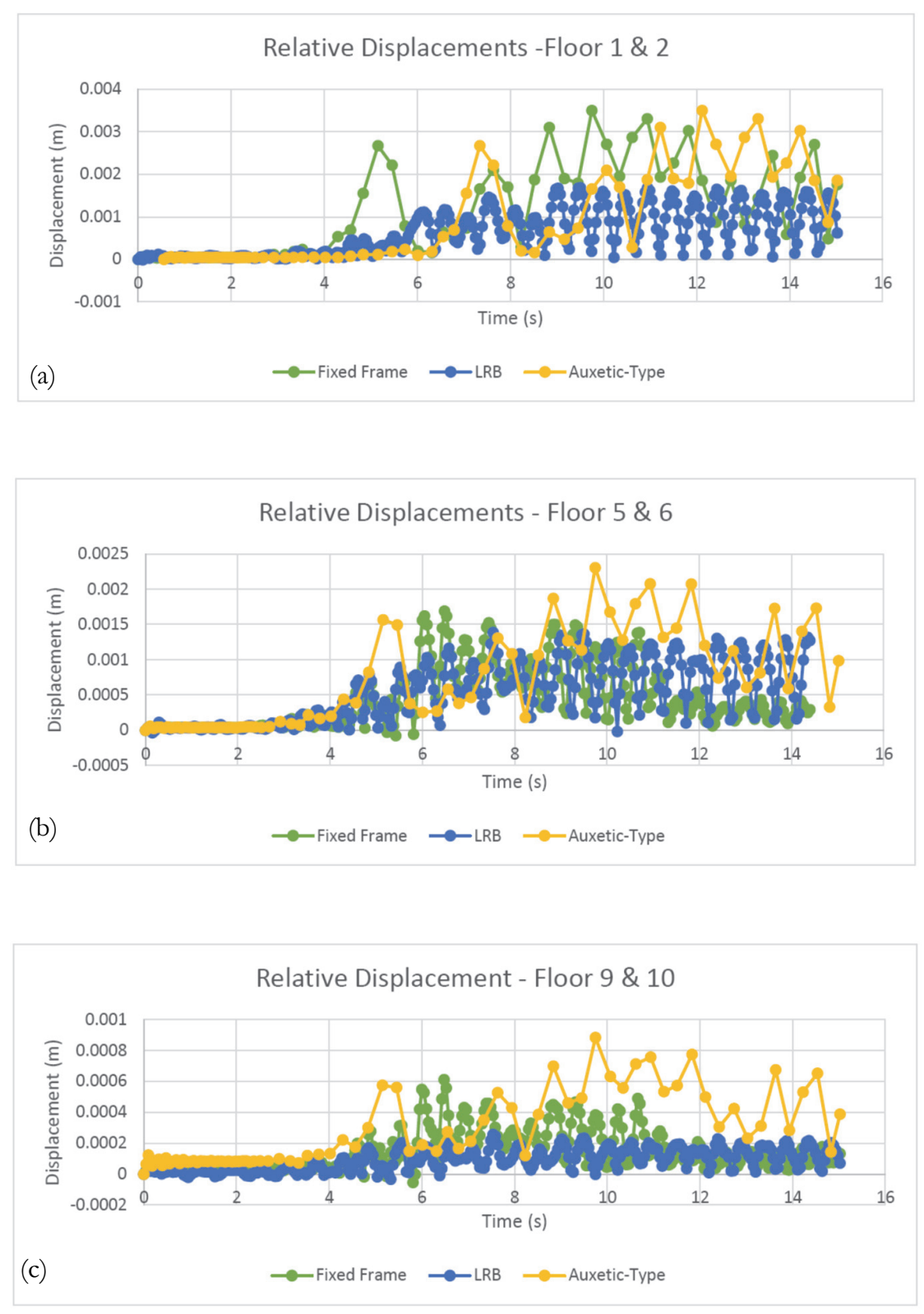

Figure 13: Relative displacement of floors (a) 1 and 2, (b) 5 and 6, (c) 9 and 10. 
Similarly, to the Northridge earthquake, Fig. 14 indicate that the auxetic-type system experienced significantly lower story accelerations when compared with the LRB and fixed base systems. On the first floor, the auxetic-type system experiences similar accelerations to the fixed base system and marginally exceeds it after $t=9.4 \mathrm{~s}$. As the story's height increases, the acceleration in the auxetic system remains more favourable than the other two systems. Towards the latter part of the earthquake, the accelerations experienced in the auxetic and fixed base systems are similar. The latter part of the earthquake is associated with consistently strong vibrations along all three axes. On the lower floors, the LRB system exhibits a performance that is less favourable than the fixed frame. However, towards the upper floors, the LRB system performs similarly to the fixed base frame and in some instances, the performance has shown an improvement.
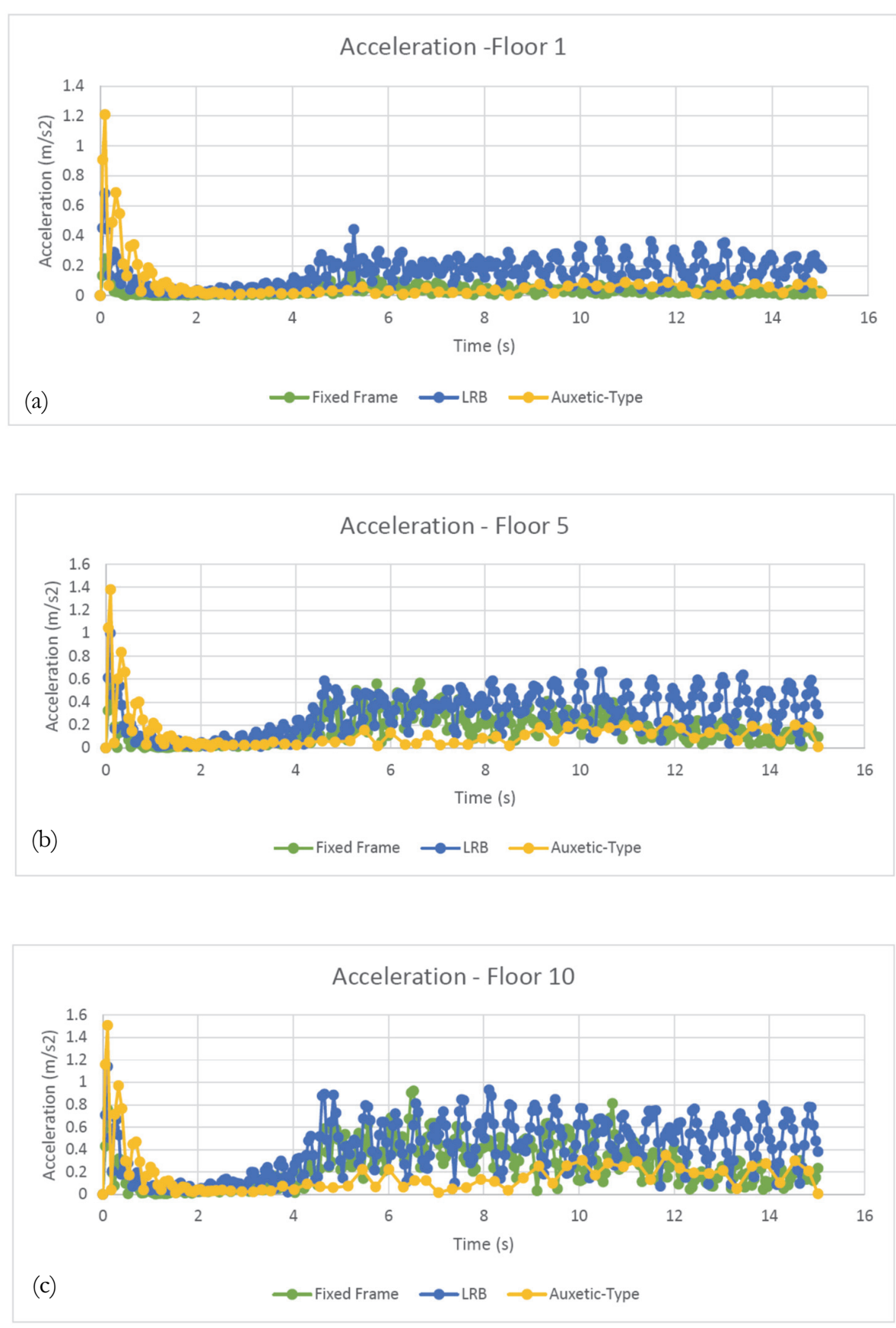

Figure 14: Acceleration on floor (a) 1, (b) 5, (c) 10 . 
- Düzce earthquake, Turkey 1999

The proposed models have also been evaluated against the magnitude 7.15 earthquake in Düzce, Turkey. The earthquake, which occurred in 1999, exhibited its most severe seismic waves towards the middle of its 43 second duration. Minor initial vibrations occur leading up to this peak. Due to this, a 15 second duration of the earthquake, which is used in the analysis, is from $t=15-30$ s. Vibrations along the $\mathrm{Y}$-Axis are most dominant in this earthquake, however vibrations in the $\mathrm{X}$-Axis remain close to that of the Y-Axis through the duration of the data used in the analysis.

It can be seen from Fig. 15 that the auxetic base isolation shows an improved performance. The general trend shows the auxetic system performing well until $\mathrm{t}=10 \mathrm{~s}$ where the relative displacements along the whole height of the superstructure are steadily lower than the ones obtained from the other two systems. LRB system displays relative displacements that are higher than the fixed frame. This indicates that the system offers an amount of lateral flexibility that is not ideal for an earthquake of this nature. The performance of the LRBs system remains almost constant throughout the analysis.
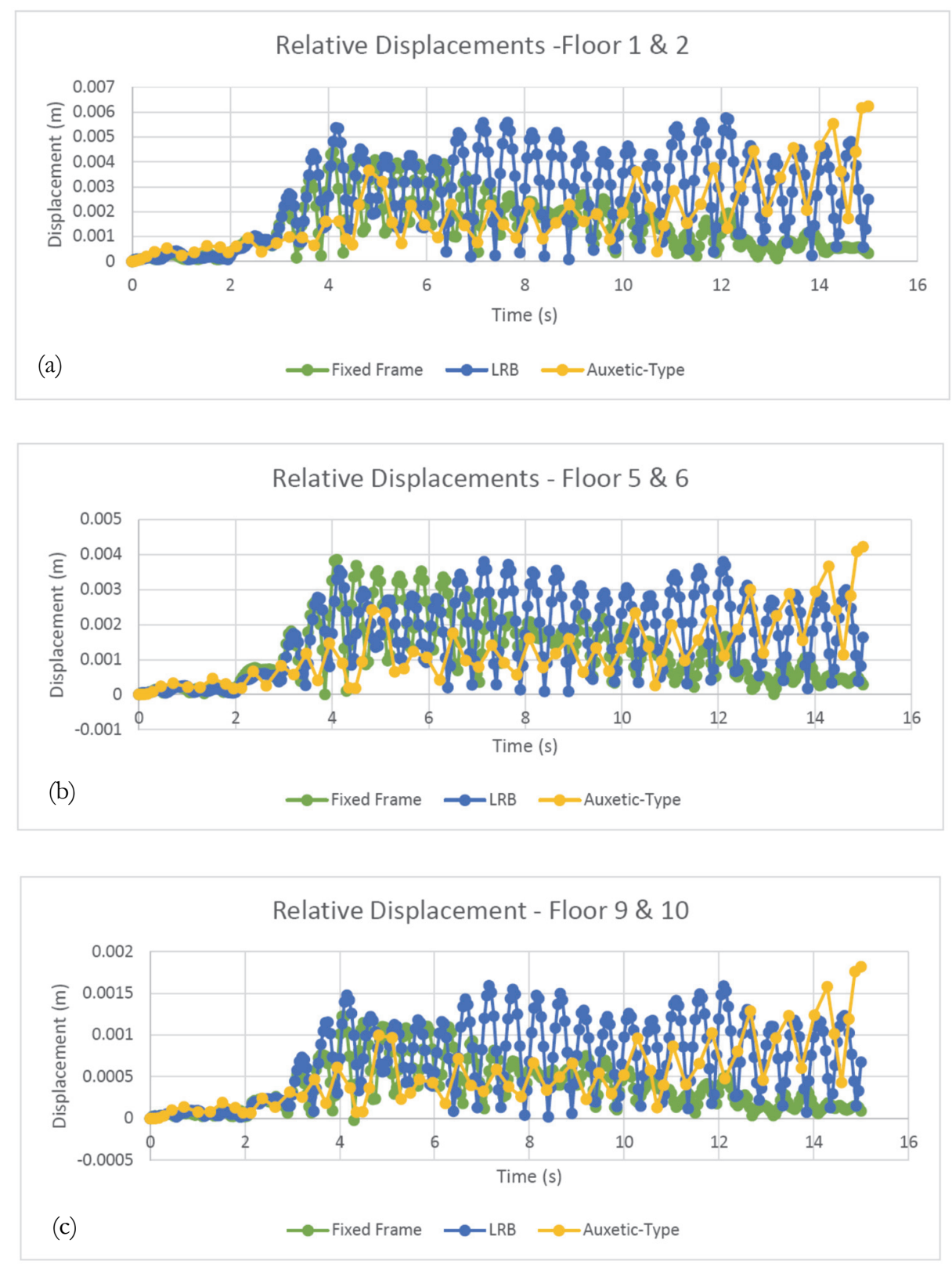

Figure 15: Relative displacement of floors (a) 1 and 2, (b) 5 and 6, (c) 9 and 10. 

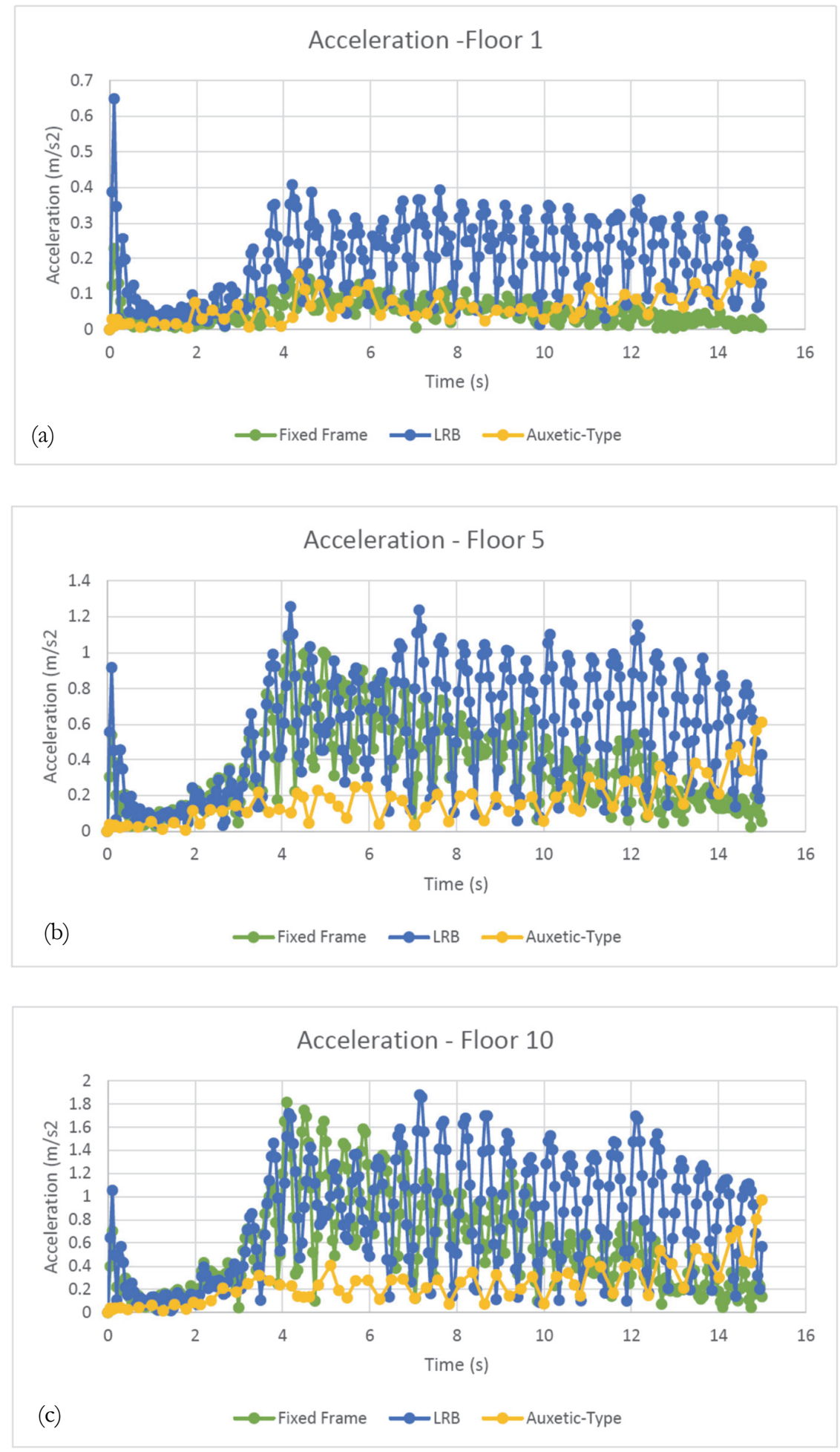

Figure 16: Acceleration on floor (a) 1, (b) 5, (c) 10.

The acceleration performance of the systems under the Düzce earthquake is shown in Fig. 16. Similarly, to the Northridge and Irpinia earthquakes, the auxetic-type system experienced significantly lower story accelerations when compared with the LRB and fixed base systems. On the first floor, the auxetic-type system experiences similar accelerations to the fixed base system, marginally exceeding it after $\mathrm{t}=13 \mathrm{~s}$. As the story height increases, the acceleration in the fixed base and LRB systems increase, however the auxetic system experiences a favourable acceleration for most of the duration of the 
earthquake. Towards the latter part of the earthquake (after $\mathrm{t}=13 \mathrm{~s}$ ), at all three levels, the accelerations experienced in the auxetic system gradually increases, exceeding that of the fixed base system. This part of the earthquake is associated with consistently strong vibrations along the $\mathrm{X}$ and $\mathrm{Y}$ axes which account for this increase.

\section{Discussion}

The relative floor displacements of the auxetic system, under the Northridge earthquake of 6.69 magnitude, have shown considerable improvements when compared to the fixed base system. The auxetic system is also shown to exhibit a gentler increase in relative displacements with an increase in height. Under the 7.15 magnitude Düzce earthquake, a similar improvement has been noted. However, under the weaker 6.9 magnitude Irpinia earthquake, the overall relative displacement performance of the auxetic system did not cause an overall improvement. This difference in results is attributed to the unique nature of each earthquake and poses an objective difficulty on the study.

The non-linear time history analysis that was performed, allows for the description of non-linear responses, such as large deformations and plastic failure on steel. The models considered in this analysis do not experience any plastic failure, thus, no steel yielding appeared. This is most likely a result of the sufficient material strength of the structural steel used in the analysis. If a similar study would be performed on less ductile structures (e.g. reinforced concrete) or on more detailed steel models, taking into account semi-rigid connections, for instance some damage would generally be expected.

Throughout the analysis of all three earthquakes, the auxetic-type system consistently performed well in reducing the story accelerations which were experienced. This result verifies past literature findings, stating that auxetic materials are capable of significantly reducing imposed vibrations.

\section{CONCLUSIONS}

I $\mathrm{n}$ this study, eigenvalue as well as non-linear time history analysis, are performed using the finite element method. Three base isolation types are simulated, namely a non-isolated fixed base system, a conventional lead-rubber bearing (LRB) and an auxetic-type isolation. The developed models consist of the base isolation system and a ten-story structural steel frame.

As mentioned in literature, auxetic materials may present the inherent mechanical property of vibration isolation, due to the nature of their microstructure. This study proposes the incorporation of re-entrant honeycomb auxetic layers into base isolation systems in order to evaluate their performance under seismic loading.

The presented investigation results in the following findings:

1. Based on the eigenvalue analysis performed in the three structural systems, it IS noted that the natural periods of the LRB and auxetic-type systems were significantly longer than that of the fixed-base structure.

2. The elongated period exhibited by the LRB and auxetic systems confirms that they will theoretically facilitate the reduction of acceleration and structural damage experienced by the structure.

3. The increased eigenperiod is related to the vibration of the superstructure as a single body, reducing in this way relative displacements which otherwise increase the elastic forces of the structure.

4. Diagrams denoting relative displacements between the floors, indicate that the auxetic-type system successfully reduces the propagation of seismic vibrations, for the two, out of the three ground motion events that are tested.

5. Diagrams denoting floor accelerations indicate that the auxetic-type system's accelerations recorded for the three simulations, are considerably lower than the fixed base frame system.

The present research can significantly be extended in different directions. Further research may explore the incorporation of three-dimensional auxetics, in similar base isolation systems. These three-dimensional structures may result in improved damping capabilities under strong impulses along each axis. Moreover, since the present research did not note any damage on the superstructure or base isolation, future research may investigate failure criteria of the auxetic base isolation system, shear stresses developed between the layers and their influence on the structural response of the superstructure. Finally, advanced numerical analysis can be conducted to properly design the auxetic base isolation, using wave propagation principles. This idea would lead to the design of a model that presents band gaps in specific, desired frequencies.

\section{REFERENCES}

[1] Varnavaa, V. and Komodromos, P. I. (2012). Analysis, design and techno-economic assessment of a base isolated steel building, In: Proceedings of the 15th World Conference on Earthquake Engineering (15WCEE), Lisbon, Portugal, 4, pp. 2586-2595. 
[2] Fallah, N. and Zamiri, G. (2012). Multi-objective optimal design of sliding base isolation using genetic algorithm, Scientia Iranica, 20(1), pp. 87-96.

[3] Chopra, A. K. (2015). Dynamics of structures: Theory and applications to earthquake engineering, 4th ed. Upper Saddle River, NJ: Prentice Hall.

[4] Kelly, T. E. (2001). Base isolation of structures. Design guidelines, Wellington, New Zealand: Holmes Consulting Group Ltd.

[5] Mir, M., Ali, M. N., Sami, J. and Ansari, U. (2014). Review of mechanics and applications of auxetic structures. Advances in Materials Science and Engineering, 2014, 753496, pp. 1-17.

[6] Dagdelen, J., Montoya, J., de Jong, M. and Persson, K. (2017). Computational prediction of new auxetic materials, Nature Communications, 8, 323.

[7] Ungureanu, B., Achaoui, Y., Enoch, S., Brûlé, S. and Guenneau, S. (2015). Auxetic-like metamaterials as novel earthquake protections, EPJ Applied Metamaterials, 2, 17.

[8] Stavroulakis, G. E. (2005). Auxetic behaviour: appearance and engineering applications, Physica Status Solidi (b), 242(3), pp. 710-720.

[9] Ma, Y., Scarpa, F, Zhang, D., Zhu, B., Chen L. and Hong, J. (2013). A nonlinear auxetic structural vibration damper with metal rubber particles, Smart Materials and Structures, 22(8), 084012.

[10] Zhang, X.-W. and Yang, D.-Q. (2016). Numerical and experimental studies of a light-weight auxetic cellular vibration isolation base, Shock and Vibration, 2016, 4017534, pp. 1-16.

[11] Scarpa, F., Giacomin, J., Zhang, Y. and Pastor, P. (2005). Mechanical performance of auxetic polyurethane foam for antivibration glove applications, Cellular Polymers, 24(5), pp. 253-268.

[12] Yang, L., Harrysson, O., West, H. and Cormier, D. (2015). Mechanical properties of 3D re-entrant honeycomb auxetic structures. International Journal of Solids and Structures, 69-70, pp. 475-490.

[13] Kaminakis, N., Drosopoulos, G.A. and Stavroulakis, G.E. (2015). Design and verification of auxetic microstructures using topology optimization and homogenization, Archive of Applied Mechanics 85, pp. 1289-1306.

[14] Drosopoulos, G.A., Kaminakis, N., Papadogianni, N. and Stavroulakis, G.E. (2016). Mechanical behaviour of auxetic microstructures using contact mechanics and elastoplasticity, Key Engineering Materials 681, pp. 100-116.

[15] Cabras, L. and Brun, M. (2014). Effective properties of a new auxetic triangular lattice: an analytical approach, Frattura ed Integrità Strutturale, 29, pp. 9-18.

[16] Wagner, P.R, Dertimanis, V.K., Antoniadis, I.A. and Chatzi, E.N. (2016). On the feasibility of structural metamaterials for seismic-induced vibration mitigation, International Journal of Earthquake and Impact Engineering, 1, 1/2.

[17] Hu, L.L., Zhou, M. and Deng, H. (2018). Dynamic indentation of auxetic and non-auxetic honeycombs under large deformation, Composite Structures, 207, pp. 323-330.

[18] Jiang, L. and Hu, H. (2017). Finite element modeling of multilayer orthogonal auxetic composites under low-velocity impact, Materials, 10(8), 908.

[19] Meng, J., Deng, Z., Zhang, K., Xu, X. and Wen, F. (2015). Band gap analysis of star-shaped honeycombs with varied Poisson's ratio, Smart Materials and Structures, 24, 095011.

[20] Hsiang-Wen, T., Wei-Di, C., Lien-Wen, C. (2017). Wave propagation in the polymer-filled star-shaped honeycomb periodic structure. Applied Physics A, 123, 523.

[21] Chen, W., Tian, X., Gao, R. and Liu, Sh. (2018). A low porosity perforated mechanical metamaterial with negative Poisson's ratio and band gaps, Smart Materials and Structures, 27, 115010.

[22] Bacigalupo, A. and De Belis, M.L. (2015). Auxetic anti-tetrachiral materials: Equivalent elastic properties and frequency band-gaps, Composite Structures, 131, pp. 530-544.

[23] Bacigalupo, A. and Gambarotta, L. (2014). A micropolar model for the analysis of dispersive waves in chiral mass-inmass lattices, Frattura ed Integrità Strutturale, 8(29), pp.1-8.

[24] Theocaris, P.S., Stavroulakis, G.E. and Panagiotopoulos, P.D. (1997). Negative Poisson's ratios in composites with starshaped inclusions: a numerical homogenization approach, Archive of Applied Mechanics 67(4), pp. $274-286$.

[25] South African Institute of Steel Construction. (2013). South African Steel Construction Handbook. 8th ed. Johannesburg: South African Institute of Steel Construction.

[26] Engineering ToolBox, (2003). Young's Modulus - Tensile and Yield Strength for common Materials. [online] Available at: https://www.engineeringtoolbox.com/young-modulus-d_417.html [15/01/2019].

[27] Materials Data Book, (2003). Cambridge University Engineering Department.

[28] Eurocode 3 (2001). Design of Steel Structures - Part 1.1: General Rules and Rules for Buildings, Brussels: European Committee for Standardization. 